\title{
Influence of the indium tin oxide/organic interface on open-circuit voltage, recombination, and cell degradation in organic small-molecule solar cells
}

\author{
Stefan Schäfer, ${ }^{*}$ Andreas Petersen, ${ }^{\dagger}$ Thomas A. Wagner, Rolf Kniprath, and Dominic Lingenfelser \\ Robert Bosch GmbH, Robert-Bosch-Platz 1, D-70839 Gerlingen-Schillerhöhe, Germany \\ Achmad Zen \\ Robert Bosch South East Asia Pte Ltd, 11 Bishan Street 21, Singapore 573943, Singapore
}

Thomas Kirchartz $z^{\ddagger}$

IEK5-Photovoltaik, Forschungszentrum Jülich, D-52425 Jülich, Germany

Birger Zimmermann and Uli Würfel ${ }^{\S}$

Fraunhofer Institute for Solar Energy Systems ISE, Heidenhofstrasse 2, D-79110 Freiburg, Germany

Xianjin Feng and Thomas Mayer

Darmstadt University of Technology, Institute of Materials Science, Petersenstrasse 23, D-64287 Darmstadt, Germany

(Received 19 December 2010; revised manuscript received 11 February 2011; published 18 April 2011)

\begin{abstract}
In this paper we investigate the performance and stability of small-molecule organic solar cells with respect to the indium tin oxide (ITO)/organic interface. Different zinc-phthalocyanine ( $\mathrm{ZnPc}) /$ fullerene $\left(\mathrm{C}_{60}\right)$ cell architectures with and without ITO $\mathrm{O}_{2}$-plasma treatment are compared and tested with respect to their degradation behavior under illumination in inert atmosphere. Photoelectron spectroscopy (UPS and XPS) shows that the $\mathrm{O}_{2}$-plasma treatment increases the ITO work function from $4.3 \mathrm{eV}$ up to $5.6 \mathrm{eV}$. We find that both the increased ITO work function as well as the introduction of an electron blocking layer between ITO and the mixed donor/acceptor layer increases the open-circuit voltage $V_{\text {oc }}$ by more than $200 \mathrm{mV}$. For both cases our continuum approach device simulation quantitatively relates the increase of $V_{\mathrm{oc}}$ to a reduced contact recombination and thus a reduced dark current. For cells built on ozone treated ITO we find a fast cell degradation caused by the UV part of the AM 1.5 spectrum. We identify the degradation, which manifests itself in a decrease of $V_{\text {oc }}$ of up to $25 \%$, as a partial reversion of the plasma induced ITO work function increase. Additionally, we demonstrate that the degradation can be reduced by structural changes in the cell architecture, leading to improved cell stability. We present a comprehensive study of the recombination at the ITO/organic interface and its influence on the open-circuit voltage and the cell stability.
\end{abstract}

DOI: 10.1103/PhysRevB.83.165311

PACS number(s): 71.23.An, 72.20.Jv, 72.80.Le, 73.50.Pz

\section{INTRODUCTION}

With power conversion efficiencies $\eta$ of around $8 \%$ organic solar cells have reached a level of maturity that makes them attractive for low cost solar energy conversion. ${ }^{1}$ The key parameters influencing the open-circuit voltage $V_{\mathrm{oc}}$ of these cells are currently under discussion. Several researchers found a strong dependence on the energy gap between the highest occupied molecular orbital (HOMO) of the donor and the lowest unoccupied molecular orbital (LUMO) of the acceptor. $^{2-4}$ The open-circuit voltage has been related to the energetic onset of the charge-transfer absorption ${ }^{5,6}$ as well as to the polarizability of the molecules. ${ }^{7}$ Depending on the cell structure, the work function of the device electrodes was found to have an influence on $V_{\mathrm{oc}}$. In bulk heterojunction (BHJ) cells, consisting of a donor/acceptor blend, the $V_{\mathrm{oc}}$ was reported to be limited by the built-in voltage $V_{\mathrm{bi}}$, which is directly linked to the work function difference of the electrodes. ${ }^{2,8-11}$ This dependence can be understood in the context of the metal-insulator-metal (MIM) model as long as no Fermi level pinning takes place. ${ }^{2}$ In contrast, for planar heterojunction (PHJ) cells recent models claim that $V_{\mathrm{oc}}$ is almost independent of the electrode work functions. ${ }^{12,13}$ This result was also supported by experimental findings. ${ }^{12,14,15}$ The models attribute the weak work function dependence of $V_{\mathrm{oc}}$ to band bending which partly compensates the change of the internal field. ${ }^{12}$ Contrary to these findings, some authors enhanced the open-circuit voltage of PHJ cells by increasing the work function difference using additional interlayers. ${ }^{10,16}$

Another significant and unsolved problem for the commercialization of small-molecule solar cells is their stability. The degradation behavior of phthalocyanine/ $\mathrm{C}_{60}$ cells was studied under the influence of ambient air ${ }^{17-20}$ and discussed regarding the interaction of oxygen with organic materials like $\mathrm{C}_{60} \cdot{ }^{21}$ Additionally, examples of cell stability measurements excluding the effects of external oxygen have been published. ${ }^{18,22-25}$ In some cases the ITO/organic interface was found to be responsible for the degradation..$^{22,23}$

Studies relating both the open-circuit voltage and the cell degradation are rare ${ }^{23}$ and a model explaining the observations quantitatively is not available. In this paper we investigate the ITO/organic interface using the well known material system $\mathrm{ZnPc}_{60}$. $\mathrm{ZnPc}$ was chosen since it leads to higher cell efficiencies compared to other metal phthalocyanines. ${ }^{26}$ We show, that ITO plasma treatment and/or altering the cell architecture causes an increase of $V_{\text {oc }}$ which we attribute 
to decreased recombination at the ITO/organic interface. A strong UV-induced cell degradation of illuminated $\mathrm{ZnPc} / \mathrm{C}_{60}$ cells under inert atmosphere is traced back to the same interface. UPS/XPS measurements on in situ plasma treated ITO prove an increasing ITO work function which is partially reversed with UV illumination, resulting in increased interface recombination.

\section{METHODS}

\section{A. Experimental methods}

$\mathrm{ZnPc} / \mathrm{C}_{60}$ heterojunction cells were produced in vacuum chambers having a base pressure of $10^{-7}$ mbar. Eight cells, each having an active area of $0.12 \mathrm{~cm}^{2}$, were evaporated in one run on the same substrate. The indium tin oxide (ITO) coated glass substrates were provided by the University of Stuttgart (roughness RMS $=0.3 \mathrm{~nm}$ and sheet resistances of $18 \Omega / \square$ ) and by Kintec (RMS $=6 \mathrm{~nm}$ and $7 \Omega / \square$ ). The ITO substrates were cleaned in ultrasonic baths with glass cleaner (Elma), deionized water, acetone, and isopropanol. Some were additionally exposed to UV ozone for $15 \mathrm{~min}$ in air or an in situ $\mathrm{O}_{2}$-plasma for $20 \mathrm{~s}$. The standard bulk heterojunction (BHJ) cell stack consists of ITO/co-evaporated ZnPc: $\mathrm{C}_{60}(1: 1$, $40 \mathrm{~nm}) / \mathrm{C}_{60}(20 \mathrm{~nm}) /$ Bphen $(9 \mathrm{~nm}) / \mathrm{Ag}(100 \mathrm{~nm})$ (see Fig. 1). The interlayer bulk heterojunction (IBHJ) cell stack features an additional $\mathrm{ZnPc}$ interlayer of $5 \mathrm{~nm}$ to $10 \mathrm{~nm}$ between the ITO and the active layer. For planar heterojunction cells (PHJ) ZnPc $(50 \mathrm{~nm}), \mathrm{C}_{60}(40 \mathrm{~nm})$, Bphen $(9 \mathrm{~nm})$, and Ag (100 nm) were subsequently deposited. ZnPc (BASF or Creaphys) and $\mathrm{C}_{60}$ (Creaphys) were both sublimed twice, while Bphen (4,7diphenyl-1,10-phenanthroline) was used as delivered (Fluka, $99 \%$ ). The deposition rate was controlled by quartz crystal monitors.

After in situ metal deposition, all cells were directly transferred into a nitrogen glove box $\left(\mathrm{O}_{2}<1 \mathrm{ppm}, \mathrm{H}_{2} \mathrm{O}<1 \mathrm{ppm}\right)$ without contact to ambient air. $J-V$ characteristics under AM 1.5 were measured. With the help of a mask it was ensured that only the active area of the respective cell was exposed to light from the solar simulator. In the degradation experiments a $J-V$ curve under illumination was recorded and after $1 \mathrm{~min}$ the dark curve was measured. This procedure was repeated 20 times and the illumination time was $22 \mathrm{~s}$ for each light curve. In order to demonstrate the importance of UV light on cell degradation, a UV filter truncating the spectrum below $400 \mathrm{~nm}$ was applied to the setup. The intensity of the solar simulator was adjusted such that a silicon reference cell showed the same reading with and without the filter. (a) $\mathrm{BHJ}$

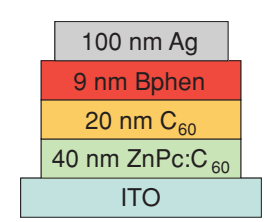

(b) IBHJ

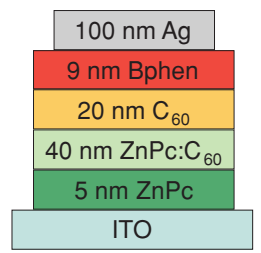

(c) PHJ

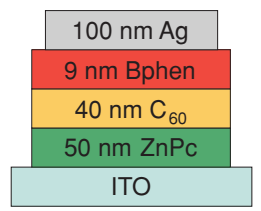

FIG. 1. (Color online) Schematic of the different cell stacks. Bulk heterojunction (BHJ) (a), interlayer bulk heterojunction (IBHJ) (b), and planar heterojunction (PHJ) (c).
Photoemission experiments were performed using a multi chamber ultrahigh vacuum (UHV) system that allowed oxygen plasma treatment, $\mathrm{C}_{60}$ deposition by thermal evaporation, and exposure to $\mathrm{UV}$ light through a $\mathrm{MgF}_{2}$ viewport. A halogen lamp providing around $100 \mathrm{~mW} / \mathrm{cm}^{2}$ or a UV-LED lamp providing around $6 \mathrm{~mW}$ at $365 \mathrm{~nm}$ was used. X-rayphotoemission spectroscopy (XPS) and ultraviolet photoemission spectroscopy (UPS) experiments were performed in an Escalab-250 system using the monochromated $K_{\alpha}$ line of an Al x-ray source (1486.6 eV, resolution $0.4 \mathrm{eV}$ ) and $\mathrm{He} \mathrm{I}$ and II resonance lines $(21.22 \mathrm{eV}$ and $40.81 \mathrm{eV}$, resolution $0.2 \mathrm{eV}$ ) from a He discharge lamp. During the UPS measurements, an electric potential of $6 \mathrm{~V}$ was applied to the samples. The spectra are given in a binding energy scale referred to the Fermi level of a sputter cleaned Ag reference sample. The work function and the valence band maxima (VBM) were found from extrapolation of the linear portion of the secondary electron cutoff and the valence band (VB) onset to background level, respectively. The base pressure during the measurements has been lower than $10^{-10}$ mbar. The interface band diagrams were constructed from the XPS and UPS data as described in Ref. 27.

\section{B. Numerical methods}

A one-dimensional macroscopic device simulation based on the drift-diffusion formalism is used to model the cell behavior and discuss the experimental results. ${ }^{11,28-32}$ The device simulator ASA, ${ }^{33}$ solves a system of three coupled differential equations: the continuity equations for electrons and holes in steady state

$$
\begin{aligned}
& \frac{\partial J_{\mathrm{n}}}{\partial x}=-q\left[G_{\mathrm{opt}}(x)-R(x)\right], \\
& \frac{\partial J_{\mathrm{p}}}{\partial x}=q\left[G_{\mathrm{opt}}(x)-R(x)\right],
\end{aligned}
$$

and the Poisson equation

$$
\Delta \varphi=-\frac{\rho}{\epsilon_{0} \epsilon_{\mathrm{r}}}
$$

which relates the electrical potential $\varphi$ to the space charge $\rho$ and the dielectric constant $\epsilon_{0} \epsilon_{\mathrm{r}}$. The optical generation rate, the recombination rate, and the elementary charge are labeled $G_{\text {opt }}(x), R(x)$, and $q$, respectively. The current densities $J_{\mathrm{n}}$ and $J_{\mathrm{p}}$ are defined as conventional currents, i.e., the direction of $J_{\mathrm{n}}$ is opposite to the direction of the actual electron flow, resulting in the minus sign in Eq. (1). The currents are driven by drift and diffusion

$$
\begin{aligned}
& J_{\mathrm{n}}=q\left(n \mu_{\mathrm{n}} F+D_{\mathrm{n}} \frac{\partial n}{\partial x}\right), \\
& J_{\mathrm{p}}=q\left(p \mu_{\mathrm{p}} F-D_{\mathrm{p}} \frac{\partial p}{\partial x}\right),
\end{aligned}
$$

where the diffusion constants $D_{\mathrm{n}, \mathrm{p}}$ are assumed to be related to the electron and hole mobilities $\mu_{\mathrm{n}}$ and $\mu_{\mathrm{p}}$ by the Einstein relation $D_{\mathrm{n}, \mathrm{p}}=\mu_{\mathrm{n}, \mathrm{p}} k_{B} T / q \cdot{ }^{34}$ The concentrations of electrons and holes are denoted as $n$ and $p$. The electric field, the temperature, and the Boltzmann constant are labeled $F, T$, and $k_{B}$, respectively. 
The four boundary conditions connecting the currents and charge carrier concentrations at the contacts are defined by a surface recombination velocity $S$. They read

$$
J_{\mathrm{n}, \mathrm{p}}(0, d)=q S\left[n(0, d), p(0, d)-n_{0}(0, d), p_{0}(0, d)\right],
$$

where the anode (hole contact) and the cathode are located at $x=0$ and $x=d$, respectively, and the device thickness is labeled $d$. The equilibrium concentrations of electrons $n_{0}$ and holes $p_{0}$ at the contacts are calculated via the injection barriers $\phi_{\mathrm{n}}$ and $\phi_{\mathrm{p}}$ assuming the Boltzmann approximation. The hole injection barrier at the anode $\phi_{\mathrm{p}}$ is defined as the energetic difference between the anode work function and the HOMO level of the adjacent hole conductor. Note that in the simulation the ITO is treated as a metal. The resulting equilibrium concentrations at the anode $(x=0)$ are

$$
\begin{gathered}
n_{0}(0)=N_{\mathrm{c}} \exp \left(\frac{-E_{\mathrm{g}}+\phi_{\mathrm{p}}}{k_{B} T}\right), \\
p_{0}(0)=N_{\mathrm{v}} \exp \left(\frac{-\phi_{\mathrm{p}}}{k_{B} T}\right),
\end{gathered}
$$

where $N_{\mathrm{c}}$ and $N_{\mathrm{v}}$ are the effective densities of states (DOS) for LUMO and HOMO, respectively. The band gap of the organic layer in contact with the electrode is named $E_{\mathrm{g}}$. For example, in case of BHJ cell, $E_{\mathrm{g}}$ at the anode is equal to the effective band gap $E_{\mathrm{g} \text {,eff }}$ of the mixed donor acceptor layer. For the cathode the equilibrium concentrations can be calculated analogously. The Boltzmann approximation is also used to relate the charge carrier concentrations and the quasi-Fermi-level $\left(E_{\mathrm{Fn}}, E_{\mathrm{Fp}}\right)$ positions inside the device via

$$
\begin{aligned}
& n=N_{\mathrm{c}} \exp \left(\frac{E_{\mathrm{Fn}}-E_{\mathrm{c}}}{k_{B} T}\right), \\
& p=N_{\mathrm{v}} \exp \left(\frac{E_{\mathrm{v}}-E_{\mathrm{Fp}}}{k_{B} T}\right) .
\end{aligned}
$$

The boundary condition for the electrical potential reads

$$
\varphi(d)-\varphi(0)=V_{\mathrm{bi}}-V,
$$

where $V_{\mathrm{bi}}$ and $V$ are the built-in voltage and the applied voltage, respectively.

An essential part of the cell physics implemented in this model is the recombination term in Eqs. (1) and (2). Three different bulk recombination pathways are considered. Direct recombination $R_{\text {direct }}$, recombination via shallow trap states $R_{\text {tail }}$ in the band tails of amorphous organic semiconductors, and recombination via traps deep inside the band gap $R_{\text {deep }}$. Hence, the total recombination can be written as

$$
R=R_{\text {direct }}+R_{\text {tail }}+R_{\text {deep }} \text {. }
$$

Direct recombination is widely used in organic solar cell models and has the form ${ }^{28,30-32,35}$

$$
R_{\text {direct }}=\xi \gamma\left(n p-n_{\mathrm{i}}^{2}\right)
$$

The recombination strength $\gamma$ is calculated according to the Langevin theory ${ }^{36}$

$$
\gamma=\frac{q}{\epsilon_{0} \epsilon_{\mathrm{r}}}\left(\mu_{\mathrm{n}}+\mu_{\mathrm{p}}\right)
$$

where $n_{\mathrm{i}}=\sqrt{n_{0} p_{0}}$ is the intrinsic charge carrier concentration. The recombination reduction factor $\xi$ accounts for an experimentally determined reduction of the recombination compared to the prediction by the Langevin theory. ${ }^{37-39}$ Recombination via trap states has been considered as a limiting factor for organic heterojunction solar cells. These traps can originate from shallow tails states ${ }^{35,40-42}$ as well as deep trap states at the donor acceptor interface. ${ }^{43,44}$ This type of recombination is suited to explain the ideality factors $n_{i d}>1^{45}$ which were experimentally determined from dark $J-V$ characteristics of organic solar cells. ${ }^{46-48}$ Despite these findings, the influence of traps on the recombination in organic heterojunction solar cells is controversially discussed. ${ }^{44,49,50}$

The following trap models originate from the literature on disordered inorganic solar cell modeling. ${ }^{51}$ Shallow trap states are simulated as exponentially decaying band tails. The resulting DOS for the acceptor-like LUMO tail states reads

$$
N_{\text {cbt }}(E)=N_{\mathrm{c}}^{\text {tail }} \exp \left(\frac{E-E_{\mathrm{c}}}{E_{\text {Urbach }}}\right) .
$$

Here, $N_{\mathrm{c}}^{\text {tail }}$ (unit: $\mathrm{m}^{-3} \mathrm{eV}^{-1}$ ) is the tail state DOS at the mobility edge and $E_{\text {Urbach }}$ is the characteristic decay energy or Urbach energy. The DOS of the donor like HOMO tail states can be calculated analogously. The recombination through the trap states in the band tail follows Shockley-Read-Hall (SRH) statistics. $^{52,53}$

The deep trap states are considered to simultaneously show donor- and acceptor-like behavior. They can be either neutral (unoccupied), negatively (occupied by an electron), or positively charged (occupied by a hole). These states are simulated by two Gaussian distributions of trap states. The one describing the $+/ 0$ transition between positive and neutral state can be expressed as

$$
N_{\text {deep }}^{+/ 0}(E)=\frac{N_{\text {deep }}^{\text {total }}}{\sigma \sqrt{2 \pi}} \exp \left(-\frac{\left(E-E_{\text {deep } 0}^{+/ 0}\right)^{2}}{2 \sigma^{2}}\right),
$$

where $N_{\text {deep }}^{\text {total }}$ (unit: $\mathrm{m}^{-3}$ ) is the total density of deep trap states and $\sigma$ is the width of the defect distribution which is centered around $E_{\text {deep } 0}^{+/ 0}=E_{\text {midgap }}-E_{\text {corr }} / 2$. Here, $E_{\text {midgap }}$ denotes the center of the band gap and $E_{\text {corr }}$ is the correlation energy. It represents the energy difference between an electron capture process by a positively charged trap compared to that by a neutral trap. For the 0/- transition between neutral and negative state a similar distribution exists which is centered around $E_{\text {deep0 }}^{0 /-}=E_{\text {midgap }}+E_{\text {corr }} / 2$. The recombination through the deep trap states follows multilevel statistics developed by Sah and Shockley. ${ }^{54}$ A complete derivation of the recombination statistics applied to the case of amorphous silicon was published by Willemen. ${ }^{55}$

The shunt currents of organic BHJ solar cells exhibit a nonlinear voltage dependence. ${ }^{56}$ This effect was recently attributed to local variations of the contact work functions resulting in single carrier injection and thus space charge limited current (SCLC) ${ }^{56}$ Based on our set of model parameters, the nonlinearity caused by SCLC is not sufficient to explain our experimental data. Hence, we employ an empirical model to 
TABLE I. Parameters used in the drift-diffusion simulation. Note that the set of parameters obtained by fitting is not unique. Especially the correlation between the mobilities and the recombination coefficients cannot be resolved from steady state data. ${ }^{55}$

\begin{tabular}{|c|c|c|c|}
\hline Parameter & Symbol & Value & Unit \\
\hline \multicolumn{4}{|c|}{ Fixed parameters } \\
\hline Effective DOS ${ }^{\mathrm{a}}$ & $N_{\mathrm{c}}, N_{\mathrm{v}}$ & $5.25 \times 10^{25}$ & $\mathrm{~m}^{-3}$ \\
\hline Tail state DOS $^{\mathrm{a}}$ & $N_{\mathrm{c}}^{\text {tail }}, N_{\mathrm{v}}^{\text {tail }}$ & $1.3 \times 10^{27}$ & $\mathrm{~m}^{-3} \mathrm{eV}^{-1}$ \\
\hline Urbach energy $^{\mathrm{a}}$ & $E_{\text {Urbach }}$ & $36.3 \times 10^{-3}$ & $\mathrm{eV}$ \\
\hline $\mathrm{ZnPc}$ band gap ${ }^{\mathrm{b}}$ & $E_{\mathrm{g}, \mathrm{ZnPc}}$ & 1.9 & $\mathrm{eV}$ \\
\hline $\mathrm{C}_{60}$ band gap $^{\mathrm{c}}$ & $E_{\mathrm{g}, \mathrm{C}_{60}}$ & 2.3 & $\mathrm{eV}$ \\
\hline Series resistance ${ }^{\mathrm{d}}$ & $R_{\mathrm{s}}$ & $9.5 \times 10^{-5}$ & $\Omega \mathrm{m}^{2}$ \\
\hline Relative static permittivity & $\epsilon_{\mathrm{r}}$ & 3.4 & - \\
\hline Contact recombination velocity & $S$ & $1 \times 10^{7}$ & $\mathrm{~ms}^{-1}$ \\
\hline Temperature & $T$ & 300 & $\mathrm{~K}$ \\
\hline \multicolumn{4}{|c|}{ Fitted parameters } \\
\hline Effective band gap & $E_{\mathrm{g}}$ & 1.311 & $\mathrm{eV}$ \\
\hline Electron injection barrier & $\phi_{\mathrm{n}}$ & 0.325 & $\mathrm{eV}$ \\
\hline Hole injection barrier for $\mathrm{ITO}_{p}$ & $\phi_{\mathrm{p}}$ & 0.253 & $\mathrm{eV}$ \\
\hline Hole injection barrier for untreated ITO & $\phi_{\mathrm{p}, \text { untreated }}$ & 0.573 & $\mathrm{eV}$ \\
\hline Electron mobility & $\mu_{\mathrm{n}}$ & $6.86 \times 10^{-5}$ & $\mathrm{~m}^{2} \mathrm{~V}^{-1} \mathrm{~s}^{-1}$ \\
\hline Hole mobility & $\mu_{\mathrm{p}}$ & $3.77 \times 10^{-6}$ & $\mathrm{~m}^{2} \mathrm{~V}^{-1} \mathrm{~s}^{-1}$ \\
\hline Density of deep trap states & $N_{\text {deep }}^{\text {total }}$ & $1.6 \times 10^{18}$ & $\mathrm{~m}^{-3}$ \\
\hline Correlation energy & $E_{\text {corr }}$ & 0.140 & $\mathrm{eV}$ \\
\hline Electron capture coefficient of neutral tail states & $C_{\mathrm{n}, 0}^{\mathrm{tail}}$ & $2.49 \times 10^{-18}$ & $\mathrm{~m}^{3} \mathrm{~s}^{-1}$ \\
\hline Hole capture coefficient of neutral tail states & $C_{\mathrm{p}, 0}^{\mathrm{n}, \mathrm{i}}$ & $3.17 \times 10^{-15}$ & $\mathrm{~m}^{3} \mathrm{~s}^{-1}$ \\
\hline Electron capture coefficient of neutral deep states & $C_{\mathrm{n}, 0}^{\text {deep }}$ & $2.07 \times 10^{-11}$ & $\mathrm{~m}^{3} \mathrm{~s}^{-1}$ \\
\hline Hole capture coefficient of neutral deep states & $C_{\mathrm{p}, 0}^{\text {deep }}$ & $5.13 \times 10^{-10}$ & $\mathrm{~m}^{3} \mathrm{~s}^{-1}$ \\
\hline Capture coefficient charged/Capture coefficient neutral & $C_{+,-} / C_{0}$ & 1790 & - \\
\hline Generation correction factor for $\mathrm{ITO}_{\mathrm{p}}$ & $c_{\mathrm{gen}}$ & 0.92 & - \\
\hline Generation correction factor for untreated ITO & $c_{\text {gen,untreated }}$ & 0.96 & - \\
\hline Parallel resistance $\mathrm{ITO}_{\mathrm{p}}$ & $R_{\mathrm{p}}$ & 13 & $\Omega \mathrm{m}^{2}$ \\
\hline Parallel resistanceuntreated ITO & $R_{\mathrm{p} \text {,untreated }}$ & 3 & $\Omega \mathrm{m}^{2}$ \\
\hline Parallel resistance voltage dependence & $C_{R_{\mathrm{p}}}$ & 0.7 & $\mathrm{~V}^{-1}$ \\
\hline Direct recombination reduction factor & $\xi$ & 0.125 & - \\
\hline
\end{tabular}

${ }^{\mathrm{a}}$ Calculated assuming the transport energy concept ${ }^{59}$ and a Gaussian DOS $\left(\sigma=75 \mathrm{meV}^{60}, N_{\text {total }}=1.7 \times 10^{27} \mathrm{~m}^{-3}{ }^{61}\right){ }^{57}$

${ }^{\mathrm{b}}$ Reference 62.

${ }^{\mathrm{c}}$ Reference 63 .

${ }^{\mathrm{d}}$ Measured on a cell layout without the organic layers, i.e. only featuring front and back contacts. ${ }^{57}$

${ }^{\mathrm{e}}$ Reference 11.

describe the voltage dependent shunt. ${ }^{57}$ The parallel resistance is given by

$$
R_{\mathrm{p}}=R_{\mathrm{p}, 0} \exp \left(-C_{R_{\mathrm{p}}} V\right),
$$

where $R_{\mathrm{p}, 0}$ is the parallel resistance at zero bias and $C_{R_{\mathrm{p}}}$ determines its voltage dependence. The optical generation rate in Eqs. (1) and (2) is calculated using a transfer matrix algorithm assuming normally incident light. ${ }^{58}$ In order to account for voltage independent, geminate recombination losses and other deviations between calculated absorption and measured current, the optical generation profile is multiplied by a constant correction factor $c_{\text {gen }}$. This factor is used as a fitting parameter. In mixed layers free charge carriers are directly generated and a field dependent charge separation efficiency is not taken into account. If light is absorbed in a pure donor or acceptor layer, excitons are created and their diffusion toward the next donor/acceptor interface is taken into account. A more detailed description of the numerical model will be published elsewhere. ${ }^{57}$ The simulations were performed using the parameter set presented in Table I. Note that the PHJ cells are not simulated using the numerical model.

\section{RESULTS}

\section{A. Effect of ITO oxygen plasma treatment on cell performance}

The device operation parameters of different cell stacks built on both untreated ITO and $\mathrm{O}_{2}$-plasma treated ITO (from now on referred to as $\mathrm{ITO}_{\mathrm{p}}$ ) substrates are summarized in Table II. Since this investigation concentrates on the influence of the ITO/organic interface, only this interface was changed in the different cell stacks. Effects related to changes of the back contact of the different cell structures are minimized by the hole blocking $\mathrm{C}_{60}$ layer shown in Fig. 1 . The $J$ - $V$ curves of BHJ and IBHJ cells are shown in Fig. 2. The plasma treatment of the ITO is found to affect the open-circuit voltage $V_{\text {oc }}$ of all three cell types. For bulk heterojunction (BHJ) cells it increases 


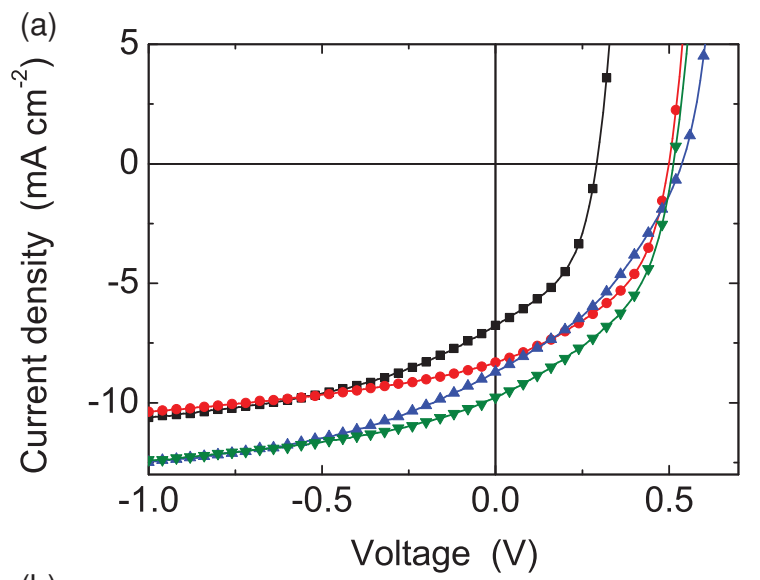

(b)

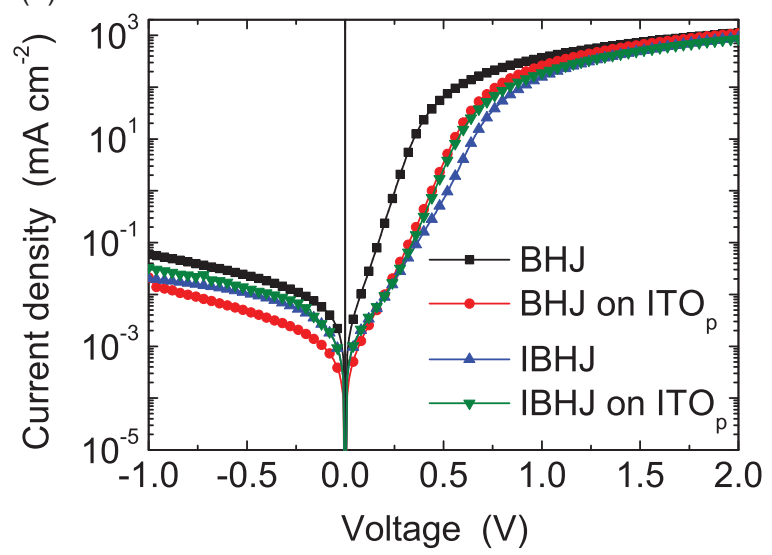

FIG. 2. (Color online) Experimental $J-V$ characteristics of BHJ and IBHJ cells with and without ITO plasma treatment measured under AM 1.5 illumination (a) and in the dark (b).

$V_{\text {oc }}$ by over $70 \%$ from about $290 \mathrm{mV}$ to $500 \mathrm{mV}$. Cells with an additional electron blocking interlayer (IBHJ) and planar heterojunction (PHJ) cells show the reverse effect. Here the value of $V_{\mathrm{oc}}$ of cells on plasma treated ITO is found to be about $4 \%$ lower compared to cells on untreated substrates.

The short-circuit currents $J_{\mathrm{sc}}$ of BHJ and IBHJ cells are about two times higher than the value measured for PHJ cells. This finding can be explained by the high donor/acceptor interface area found in mixed donor acceptor layers. ${ }^{64}$ The additional $\mathrm{ZnPc}$ layer in IBHJ cells increases $J_{\text {sc }}$ due to its additional absorption. Moreover, all the untreated samples suffered from slightly lower current compared to their plasma treated counterparts of the same stack. The fill factor $F F$ of IBHJ cells increases by more than $20 \%$ if the cell is built on plasma treated ITO $\left(\mathrm{ITO}_{\mathrm{p}}\right)$. This effect is not visible for BHJ and PHJ cells. These two cell types show no significant change in $F F$ if built on plasma treated instead of untreated ITO. The PHJ cells show more than ten percentage points higher $F F$ than the other cell stacks.

Figure 2(b) shows the effect of ITO plasma treatment on the dark $J-V$ characteristics of BHJ and IBHJ cells. In case of the $\mathrm{BHJ}$ cells the $\mathrm{O}_{2}$-plasma treatment causes a strong reduction of the dark current in the exponential region of the $J-V$ characteristic under forward bias. Compared to the untreated sample, the dark current of the plasma treated sample is reduced by more than an order of magnitude at voltages around $V_{\mathrm{oc}}$. In
TABLE II. Initial device operation parameters for different cell types as shown in Fig. 1. The cells are deposited on either untreated ITO or oxygen plasma treated ITO $\left(\mathrm{ITO}_{\mathrm{p}}\right)$ substrates.

\begin{tabular}{llcc}
\hline \hline Cell type & BHJ & IBHJ & PHJ \\
\hline Untreated ITO & & & \\
$V_{\text {oc }} / \mathrm{mV}^{-2}$ & 291 & 537 & 524 \\
$J_{\mathrm{sc}} / \mathrm{mA} \mathrm{cm}^{-2}$ & 6.76 & 8.71 & 3.63 \\
$F F / \%$ & 45.8 & 36.7 & 59.0 \\
$\eta / \%$ & 0.90 & 1.72 & 1.12 \\
Plasma treated ITO & & & \\
$V_{\text {oc }} / \mathrm{mV}^{-2}$ & 499 & 513 & 502 \\
$J_{\text {sc }} / \mathrm{mA} \mathrm{cm}^{-2}$ & 8.31 & 9.76 & 3.93 \\
$F F / \%$ & 46.0 & 44.9 & 56.3 \\
$\eta / \%$ & 1.91 & 2.25 & 1.11 \\
\hline \hline
\end{tabular}

contrast to the BHJ results, we find that the IBHJ and PHJ samples show the reverse effect. Here, the plasma treatment increases the dark current in the exponential region of the $J-V$ characteristic. An alternative ex situ UV-ozone ITO treatment in air produced the same effect on $V_{\mathrm{oc}}$ and the dark current as the aforementioned $\mathrm{O}_{2}$-plasma treatment (data not shown).

\section{B. Cell degradation under illumination}

For degradation tests, cells fabricated on ozone treated ITO were measured with and without a UV filter under simulated AM 1.5 illumination $\left(120 \mathrm{~mW} \mathrm{~cm}^{-2}\right)$ in nitrogen atmosphere. The time evolution of the cell degradation for different cell stacks is shown in Fig. 3. For better comparison $V_{\mathrm{oc}}, J_{\mathrm{sc}}, F F$, and $\eta$ have been normalized. We find that exposing the bulk heterojunction (BHJ) cells to simulated sunlight for $7 \mathrm{~min}$ causes a $25 \%$ drop in $V_{\text {oc }}$, a $9 \%$ drop in $F F$, and a short-circuit current decrease of $7 \%$. Simultaneously, at voltages around $V_{\text {oc }}$, the dark current $J_{\text {dark }}$ of the degraded BHJ cells increases by more than an order of magnitude. This increase of $J_{\mathrm{dark}}$ is similar to the one observed on the same cell stack when no plasma treatment is applied (see Fig. 2). IBHJ cells, featuring an additional $10 \mathrm{~nm}$ electron blocking interlayer, show a reduced degradation compared to BHJ cells. At voltages around $V_{\mathrm{oc}}$ the dark current of the degraded IBHJ cells was found to be increased only by a factor of two, resulting in a $V_{\mathrm{oc}}$ decrease of around $5 \%$.

The use of a UV filter effectively reduces cell degradation. BHJ cells measured with a UV filter show less than 5\% loss in $V_{\text {oc }}$ and IBHJ cells show no degradation within $7 \mathrm{~min}$. The open-circuit voltage of planar heterojunction (PHJ) cells is found to be stable when measured with a UV filter and even increases by 3\% when no filter is used [see Fig. 3(a)].

\section{Photoemission studies}

Information about the band structures of surfaces and heterojunctions can be experimentally obtained using UPS and XPS. Systematic photoemission studies of in situ magnetron sputter deposited ITO films have been carried out by Klein and coworkers, ${ }^{65-67}$ who also investigated the ITO/ZnPc interface. ${ }^{66}$ It was shown that the $\mathrm{CuPc} / \mathrm{C}_{60}$ $\mathrm{HOMO} / \mathrm{LUMO}$ lineup varies with the electrode work 

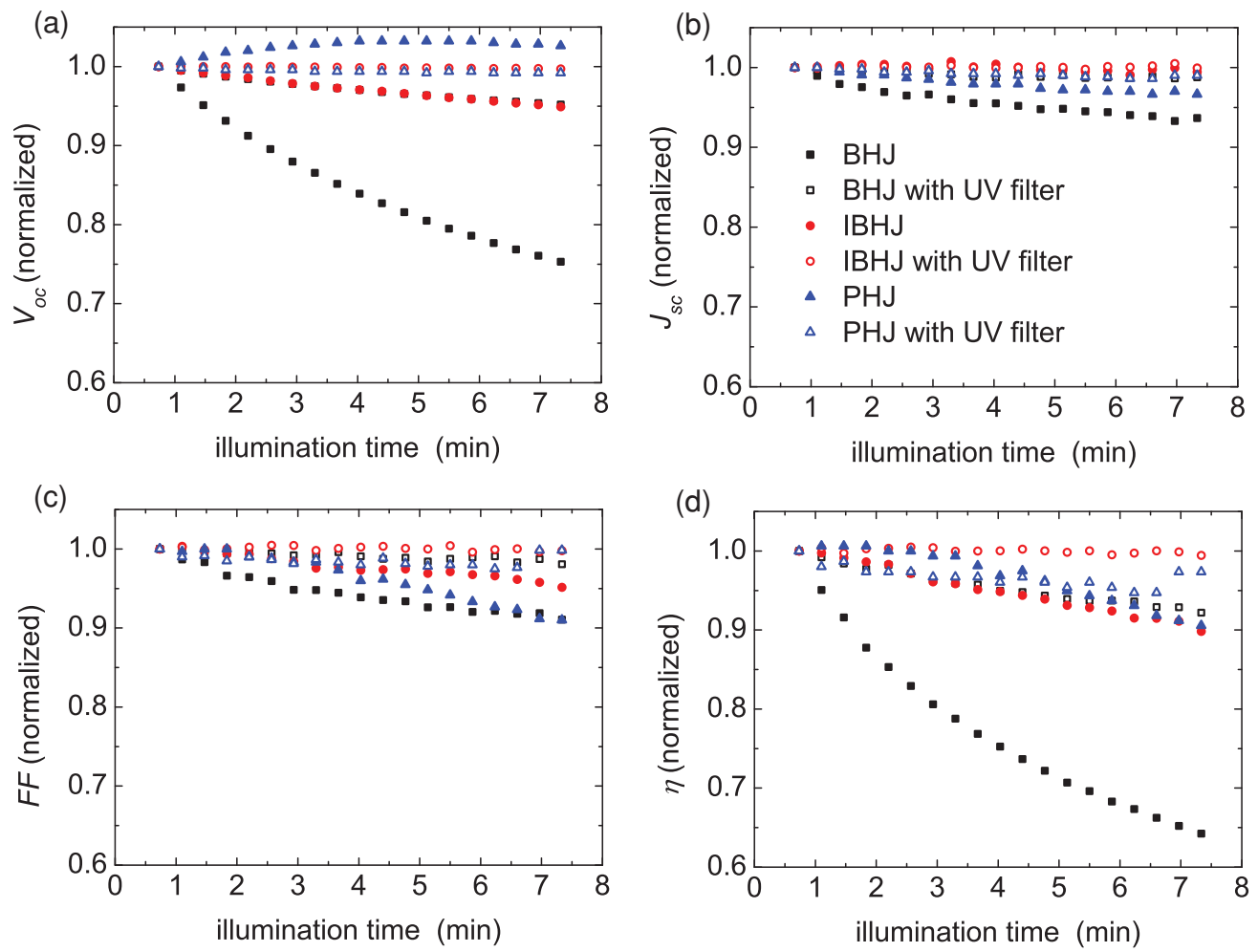

FIG. 3. (Color online) Time evolution of the open-circuit voltage $V_{\mathrm{oc}}(\mathrm{a})$, the current density at short-circuit $J_{\mathrm{sc}}(\mathrm{b})$, the fill factor $F F$ (c), and the efficiency $\eta(\mathrm{d})$ for PHJ, BHJ, and IBHJ cells fabricated on ozone-treated ITO. The cells were illuminated using an AM 1.5 solar simulator with and without a UV filter. Note that IBHJ cells with an electron blocking interlayer show no degradation when a UV filter is used.

function. ${ }^{68}$ Additionally, the metal-phthalocyanine $/ \mathrm{C}_{60}$ heterojunction has been examined. It was found that both ambient air $^{69}$ and substrate temperature during deposition ${ }^{70}$ change the electronic structure of the heterojunction. An influence on the performance of organic light emitting devices, ${ }^{71,72}$ organic solar cells ${ }^{14,73}$ and photodetectors ${ }^{74}$ has been reported for differently treated ITO substrates.

We investigate the effect of oxygen plasma treatment on the ITO and its stability under UV light as well as the electronic structure of the $\mathrm{ITO}_{\mathrm{p}} /$ organic interface under UV illumination. The ITO work function and ionization potential considerably depend on the specific crystallographic surface as has been calculated for low index surfaces ${ }^{75}$ and measured for epitaxially grown $\mathrm{In}_{2} \mathrm{O}_{3} .{ }^{76}$ We derive the ITO work function from the secondary electron onset in UPS spectra [see Fig. 4(a)]. For the corresponding band diagram of untreated ITO, drawn in Fig. 4(b), flat band situation and a small surface dipole of unknown value are assumed. Due to hydrocarbon contaminations, the measured work function of this sample appears with $4.34 \mathrm{eV}$ around $0.4 \mathrm{eV}$ smaller than for in situ prepared clean samples. ${ }^{67}$ In the band diagrams of Figs. 4(b), 4(c), 4(d) and 5(c) and 5(d) we use the revised ITO band gap value. ${ }^{77}$

We find that oxygen plasma treatment of ITO samples efficiently removes hydrocarbon surface contamination. After 2 min of plasma treatment the $\mathrm{C} 1 s$ emission is hardly detectable with XPS. After 4 min the $\mathrm{C} 1 s$ peak has completely vanished (XPS data not shown). At the same time the ITO work function increases by $1.26 \mathrm{eV}$ [see Fig. 4(a)], which is due to band bending of around $0.26 \mathrm{eV}$ and an induced surface dipole of around $1.0 \mathrm{eV}$. The band bending is indicated in both the ITO core level and the valence band maximum shifts. The results of the oxygen plasma treatment are summarized in the band diagram displayed in Fig. 4(c). An increase of the ITO work function caused by an oxygen plasma or UV-ozone treatment has also been reported by other groups. ${ }^{71-74,78,79}$ The oxidation of the surface has been proposed as a reason for the increased work function. ${ }^{78}$ We assume a gradient of the oxidation and thereby of the oxygen doping level toward the surface. However, we cannot exclude variations of the Fermi level position throughout the bulk of the film. In addition, exposure to plasma may cause electron accepting surface states. The resulting space charge layer would result in additional band bending.

A series of UPS spectra of ITO $_{p}$ samples, exposed to UV light from a halogen lamp through a UV transparent view port, is displayed in Fig. 4(a). The UV illumination gradually decreases the work function of the $\mathrm{ITO}_{\mathrm{p}}$ on a 10 min time scale. The plasma induced band bending and the surface dipole are partly reversed. The corresponding band diagram is shown in Fig. 4(d). Repeated reference UPS measurements without the external UV light show that also the UPS photons induce the reversal of the plasma induced changes, while no changes are observed on a similar time scale just by keeping the sample in UHV. About one third of the effects attributed to UV light in Fig. 4(d) is produced by the exposure to UPS photons during the measurements. Thus, the plasma induced band bending and the surface dipole are reversed either by UV or by UPS photons. UPS source induced variations of the work function have been reported before on ex situ plasma treated samples and ITO with carbon contaminations. ${ }^{80,81}$ 
(a)

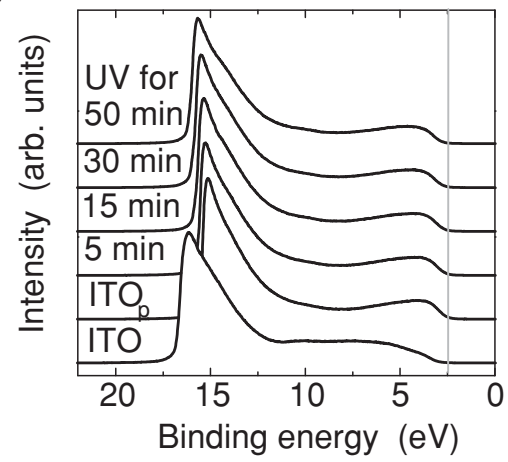

$\ln 3 d \overline{5 / 2}$

(b) ITO

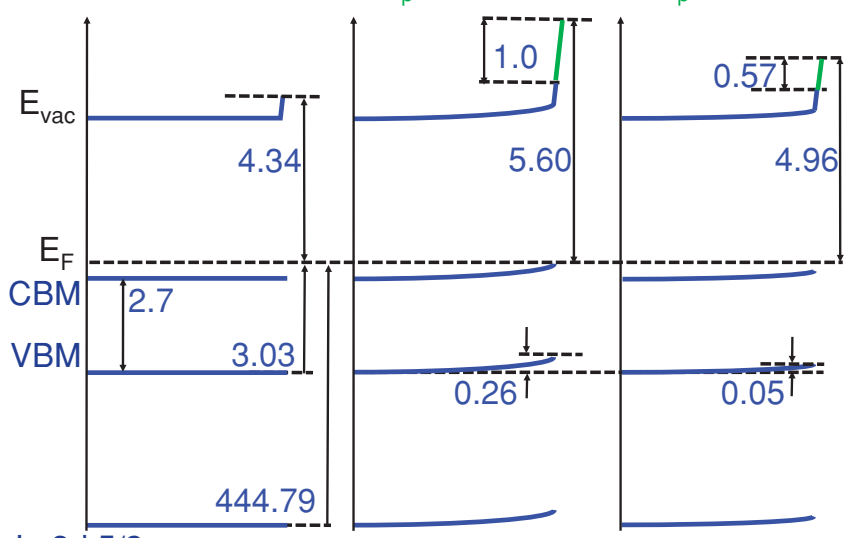

FIG. 4. (Color online) UPS spectra of ITO before and after 10 min in situ $\mathrm{O}_{2}$-plasma treatment followed by UV irradiation of up to 50 min under vacuum (a). The corresponding band diagrams for untreated ITO (b), plasma treated $\mathrm{ITO}_{\mathrm{p}}(\mathrm{c})$, and $\mathrm{ITO}_{\mathrm{p}}$ after in situ UV light exposure for $50 \mathrm{~min}(\mathrm{~d})$ are shown.

Research carried out by Fritzsche and coworkers showed that amorphous and microcrystalline indium oxide $\left(\mathrm{InO}_{\mathrm{x}}\right)$ films have the tendency to change their absorption and electrical properties under plasma treatment and exposure to UV light of $E>3.5 \mathrm{eV}$ in vacuum or an inert gas. ${ }^{82-84}$ It was found that the conductivity can be increased by about six orders of magnitude by exposing the film to UV light in vacuum. A subsequent exposure to an $\mathrm{O}_{2}$-plasma was found to restore the insulating state. Our ITO samples were measured in air before and after the plasma treatment. We observed no conductivity or transparency changes. This is in good agreement with results reported by $\mathrm{Wu}$ et al. for $\mathrm{O}_{2}$-plasma and $\mathrm{UV}$-ozone treated samples. ${ }^{71}$

For the investigation of the ITO/organic interface, we choose $\mathrm{C}_{60}$ as model organic material. By virtue of its spherical symmetry we can exclude electronic effects due to specific steric adsorption modes as observed, e.g., for $\mathrm{ZnPc} .{ }^{66}$ The band diagram of the $\mathrm{ITO}_{\mathrm{p}} / \mathrm{C}_{60}$ interface is sketched in Fig. 5(c). The energy gap of $\mathrm{C}_{60}$ is given as the distance of the $\pi$ and $\pi^{*}$ maxima positions in UPS and IPES. ${ }^{63,85}$ In this experiment $\mathrm{ITO}_{\mathrm{p}}$ showed an oxygen plasma induced dipole of $0.88 \mathrm{eV}$ and a band bending of $0.44 \mathrm{eV}$ prior to $\mathrm{C}_{60}$ deposition. The $\mathrm{C}_{60}$ deposition causes a partial reversion of the plasma induced band bending which is indicated in shifts of the In (a)

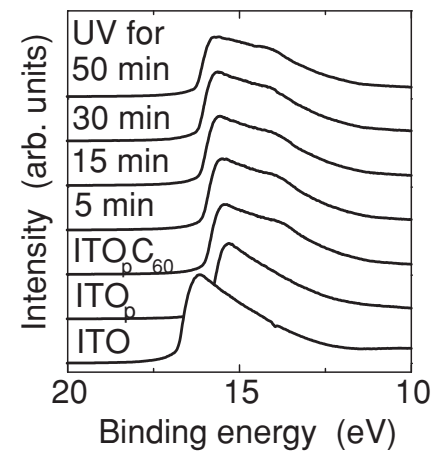

(b)

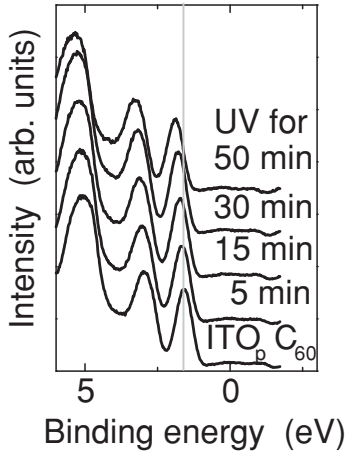

(c) $\mathrm{ITO}_{\mathrm{p}} / \mathrm{C}_{60}$

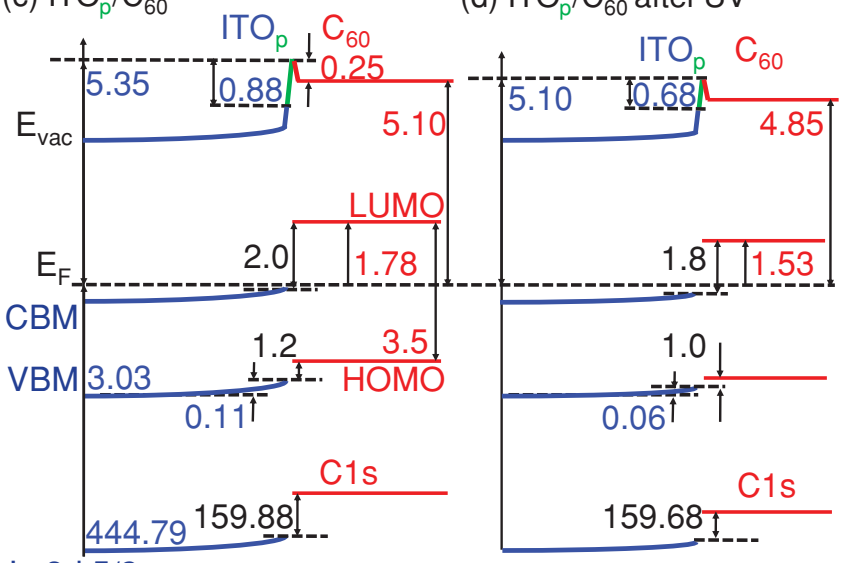

$\ln 3 d 5 / 2$

FIG. 5. (Color online) UPS spectra of the $\mathrm{ITO}_{\mathrm{p}} / \mathrm{C}_{60}$ interface showing the secondary electron cutoff measured with the $\mathrm{He}$ I (a) and the ITO VBM/ $\mathrm{C}_{60}$ HOMO measured with the He II line (b). The corresponding band lineup of the $\mathrm{ITO}_{\mathrm{p}} / \mathrm{C}_{60}$ interface before (c) and after (d) in situ UV illumination under vacuum.

$4 d$ emission (He II spectra) and of the In $3 d$ emission (XPS) for higher deposition times (data not shown). After the $\mathrm{C}_{60}$ deposition the residual $\mathrm{ITO}_{\mathrm{p}}$ band bending is $0.11 \mathrm{eV}$. In addition, the work function is reduced by a dipole of $-0.25 \mathrm{eV}$. Although it is not possible to separate different interface dipole contributions, for clarity, the $\mathrm{C}_{60}$ induced dipole is drawn in addition to the plasma induced dipole of $0.88 \mathrm{eV}$. This practice leads in the graph to a spike in the vacuum level at the $\mathrm{ITO}_{\mathrm{p}} / \mathrm{C}_{60}$ interface, the existence of which cannot be ensured experimentally. Since, in the course of the organic deposition, the $\mathrm{C}_{60}$ emissions shift almost in parallel to the ITO substrate emissions flat bands are indicated in $\mathrm{C}_{60}$.

When the $\mathrm{ITO}_{\mathrm{p}} / \mathrm{C}_{60}$ interface is exposed to UV light (halogen lamp), a shift of the $\mathrm{C}_{60}$ HOMO to higher binding energies of up to $0.25 \mathrm{eV}$ is observed [see Fig. 5(b)]. A similar shift of the secondary electron emission edge is found in the UPS spectra in Fig. 5(a). A small part of this shift (50 meV) can be assigned to a further decrease of the band bending in the $\mathrm{ITO}_{\mathrm{p}}$ substrate, as indicated by the In $3 d$ emission. The larger part $(200 \mathrm{meV})$ is caused by a change of the $\mathrm{ITO}_{\mathrm{p}} / \mathrm{C}_{60}$ interface dipole as sketched in Fig. 5(d), analog to the UV induced variation of the surface $\mathrm{ITO}_{\mathrm{p}} /$ vacuum dipole. A similar reversion of the work function has been obtained by illuminating the $\mathrm{ITO}_{\mathrm{p}} / \mathrm{C}_{60}$ interface with a UV LED $(365 \mathrm{~nm})$ 
instead of the halogen lamp. Again, part of the induced changes in the spectra have been observed without exposure to UV light indicating that the UPS source itself causes similar changes as the UV light.

\section{DISCUSSION}

\section{A. Effect of ITO oxygen plasma treatment on cell performance}

\section{Equivalent circuit model}

The strongest effect of $\mathrm{O}_{2}$-plasma treatment was observed for BHJ cells. Beside the $71 \%$ or $208 \mathrm{mV}$ increase in $V_{\text {oc }}$, the plasma treatment reduced the dark recombination current by more than an order of magnitude at voltages around $V_{\text {oc }}$. Both effects can be related using an equivalent circuit model describing the $J-V$ characteristics of a solar cell. The general form of an equivalent circuit model is

$$
J\left[V, J_{\text {photo }}(V)\right]=J_{\text {dark }}(V)-J_{\text {photo }}(V),
$$

where the voltage dependent dark recombination current is given by

$$
J_{\text {dark }}(V)=J_{0}\left[\exp \left(\frac{q V_{\text {int }}(V)}{n_{i d} k_{B} T}\right)-1\right]+\frac{V_{\text {int }}(V)}{R_{\mathrm{p}}} .
$$

Here $J_{0}, n_{i d}, J_{\text {photo }}$, and $R_{\mathrm{p}}$ are the reverse saturation current, ideality factor, photocurrent, and parallel resistance, respectively. The internal voltage $V_{\text {int }}$ differs from the applied voltage $V$ by the voltage drop at the series resistance $R_{\mathrm{s}}$

$$
V_{\text {int }}(V)=V-R_{\mathrm{s}} J(V) .
$$

Using Eqs. (18) and (19), setting $J\left(V_{\mathrm{oc}}\right)=0$ and neglecting the influence of $R_{\mathrm{s}}$ and $R_{\mathrm{p}}$, the dark current can be related to the open-circuit voltage

$$
V_{\mathrm{oc}}=\frac{n_{i d} k_{B} T}{q} \ln \left(1+\frac{J_{\mathrm{photo}}\left(V_{\mathrm{oc}}\right)}{J_{0}}\right) .
$$

Using this relation and assuming $J_{\text {photo }} \gg J_{0}$, the difference of the open-circuit voltages caused by the $\mathrm{O}_{2}$-plasma treatment $\Delta V_{\mathrm{oc}}=V_{\mathrm{oc}_{\mathrm{p}}}-V_{\mathrm{oc}_{\mathrm{u}}}$ can be written as

$$
\Delta V_{\mathrm{oc}}=\frac{k_{B} T}{q}\left[\ln \left(\frac{\left(J_{0_{\mathrm{u}}}\right)^{n_{i d, \mathrm{u}}}}{\left(J_{0_{\mathrm{p}}}\right)^{n_{i d, \mathrm{p}}}}\right)+\ln \left(\frac{\left[J_{\text {photo }_{\mathrm{p}}}\left(V_{\mathrm{oc}}\right)\right]^{n_{i d, \mathrm{p}}}}{\left[J_{\mathrm{photo}_{\mathrm{u}}}\left(V_{\mathrm{oc}}\right)\right]^{n_{i d, \mathrm{u}}}}\right)\right],
$$

where the indices $\mathrm{p}$ and $\mathrm{u}$ stand for plasma treated and untreated, respectively. Equation (22) yields information about the cause of a change in $V_{\text {oc }}$. The first term takes into account the effect of variations of the dark current, while the second term describes the voltage difference caused by the change of the photocurrent. In order to apply Eq. (22), the photocurrents at $V=V_{\mathrm{oc}}$ are needed. They can be determined using Eq. (18) and setting $J\left[V_{\text {oc }}, J_{\text {photo }}\left(V_{\text {oc }}\right)\right]=0$. Since, in our cells, the difference between internal and applied voltage at $V=V_{\mathrm{oc}}$ is only about $4 \mathrm{mV}, J_{\text {photo }}\left(V_{\mathrm{oc}}\right)$ can be approximated by $J_{\text {dark }}\left(V_{\text {oc }}\right)$. Fitting Eq. (19) to the experimental data shown in Fig. 2(b) yields the other parameters summarized in Table III.

Equation (22) reveals that the increase of the photocurrent due to the increased value of $V_{\mathrm{bi}}$ and hence a more efficient charge extraction is responsible for $56 \mathrm{mV}$ or $27 \%$ of the observed increase of $V_{\mathrm{oc}}$. The remaining $152 \mathrm{mV}$ or $73 \%$ can be
TABLE III. Parameters obtained by fitting Eq. (19) to the BHJ data shown in Fig. 2(b) and assuming $T=300 \mathrm{~K}$. $J_{\text {photo }}\left(V_{\text {oc }}\right)$ is approximated by $J_{\text {dark }}\left(V_{\mathrm{oc}}\right)$.

\begin{tabular}{lcc}
\hline \hline Parameter & BHJ on untreated ITO & ${\text { BHJ on } \text { ITO }_{\mathrm{p}}}$ \\
\hline$n_{i d}$ & 1.36 & 1.84 \\
$R_{\mathrm{S}} / \Omega \mathrm{m}^{2}$ & $1.42 \times 10^{-4}$ & $1.14 \times 10^{-4}$ \\
$R_{\mathrm{p}} / \Omega \mathrm{m}^{2}$ & 11 & 2.1 \\
$J_{0} / \mathrm{A} \mathrm{m}^{-2}$ & $7.38 \times 10^{-3}$ & $1.08 \times 10^{-3}$ \\
$J_{\text {photo }}\left(V_{\text {oc }}\right) / \mathrm{A} \mathrm{m}^{-2}$ & 25.82 & 35.52 \\
\hline \hline
\end{tabular}

attributed to the decreased value of $J_{0}$ and thus to a decreased dark current. Since the dark current is not necessarily related to $V_{\mathrm{bi}}$, only $27 \%$ of the increase of $V_{\mathrm{oc}}$ can be directly attributed to the change of the built-in voltage.

\section{Drift-diffusion device model}

In order to quantitatively explain the mechanisms leading to the reduction of the dark current and thus of $J_{0}$, the drift diffusion model is fitted to the $J-V$ characteristics of the BHJ cells built on both untreated and plasma treated ITO. Within the frame of this model $J_{\text {dark }}$ can be divided into three contributions, two of which are shown in Fig. 6(a):

$$
J_{\text {dark }}=J_{\text {dark }_{\text {shunt }}}+J_{\text {dark }_{\text {bulk }}}+J_{\text {dark }_{\text {contact }}} .
$$

The first term denotes the current flowing through shunt paths. The second contribution is the bulk recombination current,

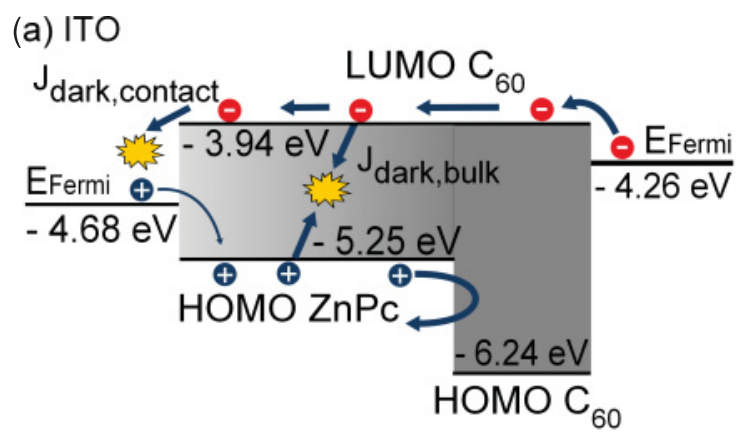

(b) $I T O_{p}$

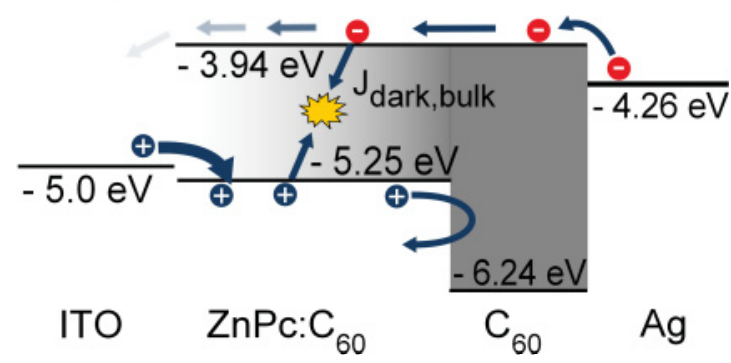

FIG. 6. (Color online) Simplified band diagram for a $\mathrm{ZnPc} / \mathrm{C}_{60}$ BHJ cell built on untreated ITO (a) and plasma-treated ITO (b) showing the main recombination paths for the dark current. Only the effective band gaps are sketched and for clarity the ITO and Bphen/Ag contacts are treated as metals. The opacity of the background depicts the electron equilibrium concentration. The Fermi energy of the $\mathrm{Ag}$ and the $\mathrm{C}_{60}$ band gap are taken from Refs. 86 and 63, respectively. The other values originate from the simulation (see Table I). 
which is carried by electrons and holes recombining at the interface of donor and acceptor molecules. It is equal to the spatial integral over the recombination rate from Eq. $(12)^{45}$ :

$$
J_{\text {dark }_{\text {bulk }}}=q \int_{0}^{d} R(x) d x .
$$

The third contribution is called contact recombination current. It consists of electrons (holes) traveling from the cathode (anode) through the whole device subsequently recombining at the anode (cathode). This type of dark recombination can be suppressed by introducing selective contacts, i.e., electron and hole blocking layers, at the electrodes. Following Eq. (6) it can be written as

$$
J_{\text {dark }_{\text {contact }}}=q S\left[n(0)-n_{0}(0)\right]+q S\left[p(d)-p_{0}(d)\right] .
$$

The first term of Eq. (25) describes electrons recombining at the anode $(x=0)$ and the second term stands for holes recombining at the cathode $(x=d)$.

Figure 7 shows the excellent agreement of experimental data and simulation. The input parameter sets for the simulation of the two cells differ in three parameters only, namely, the optical generation correction factor $c_{\text {gen }}$, the parallel resistance $R_{\mathrm{p}}$ and the hole injection barrier $\phi_{\mathrm{p}}$. For $c_{\text {gen }}$ a difference of $4 \%$ was found. This difference originates most likely from
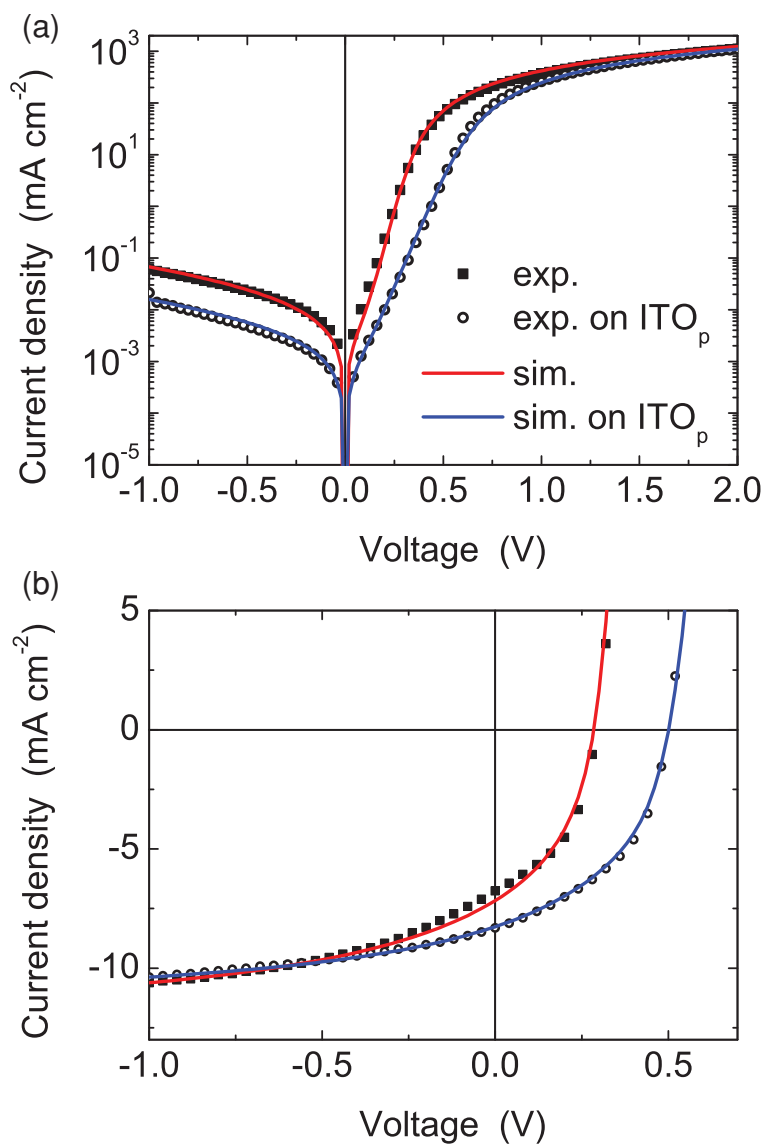

FIG. 7. (Color online) Comparison of measured and simulated $J-V$ characteristics of $\mathrm{BHJ}$ cells built on plasma treated and untreated ITO: cells measured in the dark (a) and the same cells measured under AM 1.5 illumination (b). The simulations were performed using the parameters shown in Table I.
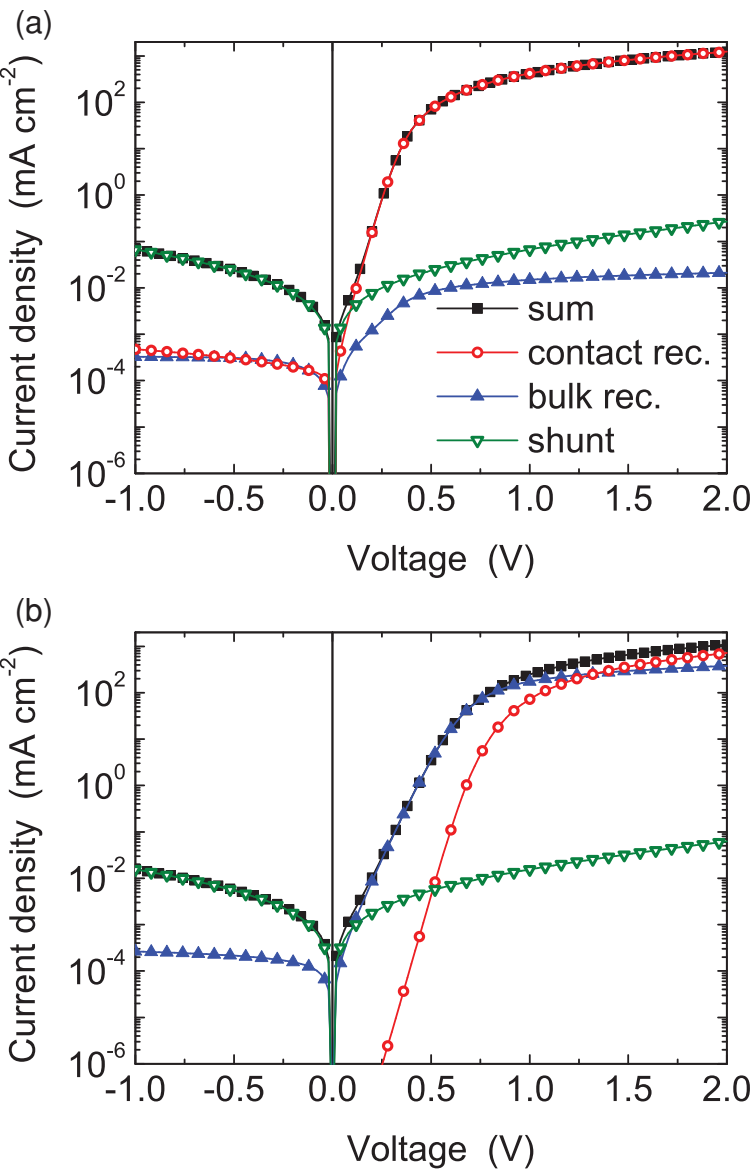

FIG. 8. (Color online) Simulated dark recombination broken down to its contributions for BHJ cells fabricated on untreated ITO (a) and cells made on $\mathrm{ITO}_{\mathrm{p}}$ (b).

small deviations in the layer thickness and active cell area. The difference in the parallel resistance, with $R_{\mathrm{p}}=3 \Omega \mathrm{m}^{2}$ and $R_{\mathrm{p}}^{\text {untreated }}=13 \Omega \mathrm{m}^{2}$, accounts for the experimentally observed scattering of $J_{\text {dark }}$ under reverse bias. We found that cells showing identical dark $J-V$ characteristics under forward bias differ by more than an order of magnitude in their current under reverse bias. We attribute this behavior to lateral inhomogeneities of the shunt resistance, which cannot be modeled directly in a one dimensional simulation. These changes in $R_{\mathrm{p}}$ have no influence on the $J-V$ characteristics under forward bias as can be seen in Fig. 8 .

The simulation yields a value of $320 \mathrm{meV}$ for the change of the hole injection barrier due to ITO plasma treatment. This is less than the work function change of $1.26 \mathrm{eV}$ measured via XPS/UPS on plain ITO (see Fig. 5), but it is consistent with findings by Kahn et al. ${ }^{87}$ For ZnPc they reported that the change of the Fermi energy is only about $25 \%$ of the work function change of the adjacent electrode. They explained this behavior by the formation of a strong interface dipole, similar to the $\mathrm{C}_{60}$ dipole shown in Fig. 5. Using this estimate, one would expect that the change of the hole injection barrier does not exceed $315 \mathrm{meV}$. This is reasonably close to the value we determined by fitting. The complete set of parameters simultaneously describing the cell response of the BHJ cells fabricated on treated and untreated ITO is shown in Table I. 
A description of the fitting procedure will be published elsewhere. ${ }^{57}$

These simulation results verify that both the decrease in dark recombination and the increase of $V_{\mathrm{oc}}$ can be quantitatively explained by the plasma induced increase of the ITO work function. Our findings are in agreement with previously published results. Xue et al. observed a similar reduction of the dark current caused by an oxygen plasma induced increase of the ITO work function for small molecule photodetectors. ${ }^{74}$ Instead of changing the work function by an ITO treatment, a $\mathrm{MoO}_{3}$ layer ${ }^{16}$ or a doped organic transport layer ${ }^{10}$ next to the electrode can be used to control the Fermi level at the anode and thus the $V_{\mathrm{oc}}$.

\section{Recombination in BHJ cells}

Apart from relating the variation of the ITO work function to the changes in the cell behavior, the simulation is also able to explain the mechanism behind these changes. Figure 8 shows the simulated dark recombination current broken down into its three components [see Eq. (23)]. If untreated ITO is used [see Fig. 8(a)], the dark recombination current under forward bias is dominated by contact recombination, i.e., electrons recombining at the anode. The ideality factor of the contact recombination is $n_{i d} \approx 1$ because the contact recombination and the electron concentration at the anode are given by Eq. (6) and $n(0) \propto \exp \left[(q V) /\left(k_{B} T\right)\right]$, respectively. In contrast, cells with $\mathrm{ITO}_{\mathrm{p}}$ show an ideality factor of $n_{i d} \approx 2$. This is the value expected for recombination via defects in the middle of the band gap ${ }^{88}$ or via a broad Gaussian density of states. ${ }^{89}$ Figure 8 (b) reveals that for $0<V<$ $V_{\text {oc }}$ bulk recombination is the dominant process in $\mathrm{ITO}_{\mathrm{p}}$ based cells. The simulation also shows that, in accordance with the ideality factor, recombination via deep trap states dominates the bulk recombination in this voltage range (not shown). Although the above mentioned findings indicate a recombination mechanism involving sub-band-gap states, an unambiguous experimental proof for the recombination mechanism in organic solar cells has not been published. An overview on the discussion of different experimental methods and their interpretations can be found in Refs. 44,49,50 and references therein. A more detailed discussion of this matter in the context of device modeling exceeds the scope of this work and will be published elsewhere. ${ }^{57}$

Figure 6 shows the underlying mechanism. The electron equilibrium concentration close to the ITO/organic interface depends exponentially on the ITO work function [Eq. (7)]. For cells built on untreated ITO, the high electron equilibrium concentration next to this interface allows for significant contact recombination at the ITO. This is described by the first term of Eq. (25) [see Fig. 6(a)]. The simulation shows that the bulk recombination of injected charge carriers is negligible in this cell type because the high contact recombination prevents significant charge buildup [see Fig. 8(a)]. According to our simulation the increase of the ITO work function, induced by plasma treatment, reduces the electron equilibrium concentration at the ITO/organic interface by four orders of magnitude and acts as a passivation for the anode. As a consequence BHJ cells fabricated on $\mathrm{ITO}_{\mathrm{p}}$ show no significant contact recombination for voltages up to $V_{\mathrm{oc}}$. At higher forward voltages the contact recombination again becomes the dominant recombination mechanism. Having $n_{i d} \approx 1$, it grows more rapidly with applied voltage than the trap dominated bulk recombination [see Fig. 8(b)].

\section{Recombination in IBHJ and PHJ cells}

IBHJ cells on untreated ITO show high values of $V_{\text {oc }}$ and a low $J_{\text {dark }}$ (see Fig. 2). The introduction of an electron blocking $\mathrm{ZnPc}$ interlayer passivates the anode and suppresses the contact recombination. This leaves $J_{\text {dark }_{\text {bulk }}}$ as the only significant source of dark recombination, resulting in a higher $V_{\mathrm{oc}}$ as explained before for the $\mathrm{BHJ}$ cells built on $\mathrm{ITO}_{\mathrm{p}}$. In contrast to the $\mathrm{O}_{2}$-plasma treatment, the $\mathrm{ZnPc}$ interlayer suppresses $J_{\text {dark }}$ without increasing the built-in voltage $V_{\mathrm{bi}}$. Thus, less driving force is available to extract the photogenerated charge carriers. This results in increased recombination of photocharges and a reduced $F F$. Hence, in cells with insufficient $V_{\text {bi }}$, the interlayer increases $V_{\mathrm{oc}}$ at the expense of the $F F$.

If $\mathrm{ITO}_{\mathrm{p}}$ is used, the additional $\mathrm{ZnPc}$ interlayer has no significant effect on the dark $J-V$ characteristics [compare Fig. 2(b)] since the contact recombination has already been suppressed by the low electron concentration at the anode. In this case the interlayer only causes an increase of $J_{\mathrm{sc}}$ due to additional absorption. In contrast to the untreated IBHJ cell, $V_{\text {bi }}$ is sufficiently high to ensure field driven extraction and low recombination of the photocharges. A similar enhancement of the open-circuit voltage due to reduced dark recombination was reported by $\mathrm{Li}$ et al. for PHJ cells. ${ }^{90}$ They found that $\mathrm{SnPc} / \mathrm{C}_{60}$ cells show an increased dark current caused by electron leakage currents from cathode to anode. An electron blocking LUMO offset, passivating the anode, resulted in the same characteristic increase of the ideality factor as we observe for the $\mathrm{ITO}_{\mathrm{p}}$ based BHJ cells.

Unlike the other cell stacks, PHJ cells are found to be almost insensitive to the plasma and UV-ozone treatment. They show no significant change in $V_{\text {oc }}$ and $F F$. This is in good agreement with previously published experimental and theoretical findings. ${ }^{12,14}$ As in the IBHJ cell stack, there is no direct contact between the electron (hole) transport layer and the anode (cathode) in PHJ cells. As a result $J_{\text {dark }}$ contact is suppressed and $J_{\text {dark }}$ is dominated by bulk recombination. Compared to the IBHJ type cells the PHJ cells show no increase in $F F$, when built on plasma treated ITO. This may be a result of the low donor/acceptor interface area found in PHJ cells. Since recombination of photogenerated charge carriers takes place at this interface, a smaller interface area will cause less recombination even if the external voltage is close to $V_{\mathrm{bi}}$.

In summary, we find that for an unpassivated anode the intrinsically low ITO work function causes a high contact recombination which results in a high dark current and thus a low $V_{\text {oc }}$. If the ITO work function is increased by an $\mathrm{O}_{2}$-plasma treatment, the low electron concentration next to the ITO reduces the contact recombination and thus acts as a passivation for the anode. This finding agrees with the metal-insulator-metal (MIM) model which states that $V_{\text {oc }}$ linearly depends on the work function difference of the electrodes. ${ }^{8}$ Contrary to that we find that $V_{\text {oc }}$ can also be increased independently of $V_{\text {bi }}$ by passivating the anode using an electron blocking interlayer. In case the open-circuit voltage 
is increased without increasing $V_{\mathrm{bi}}$ and if the remaining built-in field does not provide enough driving force for efficient charge extraction, the $F F$ is reduced. This demonstrates the MIM model is not applicable for cells with passivated contacts. In general, the MIM model can only be used if recombination at the contacts significantly exceeds the losses in the bulk of the material, i.e., the cell has to be limited by contact recombination.

\section{B. Cell degradation under illumination}

The fast cell degradation of BHJ cells built on ozone treated ITO displayed in Fig. 3 is mainly caused by UV light. The UV part of the AM 1.5 spectrum is identified as the main cause of degradation since the use of a $400 \mathrm{~nm}$ cut-off UV filter reduces the degradation significantly. Stability enhancing effects by UV protection have been previously reported by Sullivan et al. for pentacene/ $\mathrm{C}_{60}$ PHJ cells. ${ }^{22}$ They attributed the degradation to a UV induced annealing and reorganization process at the ITO/organic interface and thereby a worsened contact. In our cells we find an increase of the dark current after illumination with UV light. Contrary to the mechanism proposed by Sullivan et al., this increased dark current indicates a better conductivity of the ITO/organic interface.

We attribute the degradation effect to a UV induced reduction of the ITO work function. Hence, it is the reverse process of the ITO $\mathrm{O}_{2}$-plasma or ozone treatment. The UPS/XPS measurements presented in Fig. 4 show that UV radiation reduces the work function of ITO substrates priorly treated with $\mathrm{O}_{2}$-plasma $\left(\mathrm{ITO}_{\mathrm{p}}\right.$ ) and thus partly reverses the plasma treatment. In addition, when the $\mathrm{ITO}_{\mathrm{p}}$ is in contact with a $\mathrm{C}_{60}$ layer, we find that $\mathrm{UV}$ exposure increases the injection barrier for holes. Thus, the electron density at the anode increases (see Fig. 5). Following the line of argument, as presented in the previous section, the measured reduction of the work function also covers the observed changes in cell behavior. For BHJ type cells the degradation manifests itself mainly in two features, namely an increase of the dark current $J_{\text {dark }}$ under forward bias conditions and a resulting decrease of $V_{\text {oc }}$. This increase of $J_{\text {dark }}$ is, though less pronounced, similar to the effect observed for BHJ cells without ITO plasma treatment [see Fig. 2(a)]. Thus, from the point of cell behavior, the degradation also appears to be a partial reversion of the oxygen induced work function increase. A similar degradation was found by Heutz et al. for $\mathrm{CuPc} / \mathrm{C}_{60} \mathrm{BHJ}$ cells measured in ambient air. ${ }^{18}$ The authors attributed the degradation in $V_{\text {oc }}$ and $J_{\text {sc }}$ to traps generated throughout the active layer by external oxygen. This explanation is not applicable to our results since our experimental setup excludes the effects of ambient air and oxygen.

IBHJ and PHJ cells show significantly less degradation compared to BHJ devices (see Fig. 3). This is consistent with our degradation theory since we find that for these cell types $V_{\text {oc }}$ does not depend on the ITO work function (see Table II). The simulation shows that, after the partial reversion of the work function, the remaining built-in field still provides an efficient extraction of the photo charge carriers. As a result, the $F F$ of the degraded IBHJ cells is only reduced by $5 \%$ whereas a $20 \%$ change is observed between cells with and without ITO plasma treatment. For PHJ cells we observe a UV induced increase of $V_{\mathrm{oc}}$, which is consistent with the decrease of $V_{\mathrm{oc}}$ observed after plasma treatment (see Table II). The explanation for this effect will be published elsewhere. ${ }^{57}$

In contrast to the cell behavior shown in Table II, we find that UV radiation lowers the $F F$ and thus the efficiency of the PHJ devices by about $10 \%$. Since we find the $F F$ to be more stable if a UV filter is used, this may indicate another, though less pronounced, UV induced degradation mechanism. The stability of similar PHJ devices made of $\mathrm{CuPc} / \mathrm{C}_{60}$ and measured under illumination in vacuum was previously published by Heutz et al. ${ }^{18}$ An alternative to the unstable $\mathrm{O}_{2}$-plasma treatment is the control of the work function by introducing a $\mathrm{MoO}_{3}$ interlayer between ITO and the organic layers. Kanai et al. reported a high $V_{\text {oc }}$ and $F F$ as well as an enhanced stability under illumination for this configuration. $^{23}$

\section{CONCLUSION}

We investigated the effect of the ITO/organic interface on the performance and stability of organic $\mathrm{ZnPc} / \mathrm{C}_{60}$ solar cells. Their open-circuit voltage $V_{\text {oc }}$ can be increased either by an $\mathrm{O}_{2}$-plasma treatment of the ITO or by introducing an electron blocking layer between the ITO and the mixed donor/acceptor layer.

Photoelectron spectroscopy (UPS/XPS) measurements confirm that the ITO work function and thus the built-in voltage $V_{\mathrm{bi}}$ is increased by an $\mathrm{O}_{2}$-plasma treatment. We show, by means of a continuum approach device simulation, that the increase of $V_{\mathrm{oc}}$ is the result of a reduced contact recombination at the anode (hole contact). Additionally, we quantitatively relate the reduced contact recombination to the low equilibrium concentration of the minority charge carriers. This low equilibrium concentration of electrons at the anode and thus the high $V_{\mathrm{oc}}$ can be achieved either by a high $V_{\mathrm{bi}}$ or by an electron blocking layer. We find that if $V_{\text {oc }}$ approaches $V_{\mathrm{bi}}$, the insufficient driving force results in an accumulation of photogenerated charges and thus in a reduction of the $F F$.

Both UPS/XPS measurements and cell data confirm that the ITO work function change, induced by the oxygen treatment, is only partly stable under UV radiation. For BHJ cells built on ozone treated ITO we find a fast cell degradation caused by the UV part of the solar spectrum. We show that this degradation process, which mainly affects $V_{\text {oc }}$, can be explained as a partly reversion of the oxygen induced ITO work function increase.

\section{ACKNOWLEDGMENTS}

The authors thank Stephen En Rong Tay, Nguyen Thi Minh Hieu, and Mathias Geissler for their help with cell measurements and Alexandros Dimopoulos for the helpful discussions. We also thank the BMBF for the financial support in the framework of the OPEG project (13N9715). T.K. acknowledges support by an Imperial College Junior Research Fellowship. 
*Present address: Freiburg Materials Research Centre, Stefan-Meier-Strasse 21, D-79104 Freiburg, Germany; stefan.schaefer@de.bosch.com.

† andreas.petersen@de.bosch.com

${ }^{\ddagger}$ Present address:Blackett Laboratory of Physics, Imperial College, South Kensington, London SW7 2AZ, UK.

${ }^{\S}$ Freiburg Materials Research Centre, Stefan-Meier-Strasse 21, D79104 Freiburg, Germany.

${ }^{1}$ M. A. Green, K. Emery, Y. Hishikawa, and W. Warta, Prog. Photovolt: Res. Appl. 19, 84 (2011).

${ }^{2}$ C. J. Brabec, A. Cravino, D. Meissner, N. S. Sariciftci, T. Fromherz, M. T. Rispens, L. Sanchez, and J. C. Hummelen, Adv. Funct. Mater. 11, 374 (2001).

${ }^{3}$ B. P. Rand, D. P. Burk, and S. R. Forrest, Phys. Rev. B 75, 115327 (2007).

${ }^{4}$ A. Gadisa, M. Svensson, M. Andersson, and O. Inganäs, Appl. Phys. Lett. 84, 1609 (2004).

${ }^{5}$ K. Vandewal, K. Tvingstedt, A. Gadisa, O. Inganäs, and J. V. Manca, Nat. Mater. 8, 904 (2009).

${ }^{6}$ K. Vandewal, A. Gadisa, W. D. Oosterbaan, S. Bertho, F. Banishoeib, I. Van Severen, L. Lutsen, T. J. Cleij, D. Vanderzande, and J. V. Manca, Adv. Funct. Mater. 18, 2064 (2008).

${ }^{7}$ I. Bruder, A. Ojala, C. Lennartz, S. Sundarraj, J. Schöneboom, R. Sens, J. Hwang, P. Erk, and J. Weis, Sol. Energy Mater. Sol. Cells 94, 310 (2010).

${ }^{8}$ V. D. Mihailetchi, P. W. M. Blom, J. C. Hummelen, and M. Rispens, J. Appl. Phys. 94, 6849 (2003).

${ }^{9}$ K. Kawano, N. Ito, T. Nishimori, and J. Sakai, Appl. Phys. Lett. 88, 073514 (2006).

${ }^{10}$ C. Uhrich, D. Wynands, S. Olthof, M. K. Riede, K. Leo, S. Sonntag, B. Maennig, and M. Pfeiffer, J. Appl. Phys. 104, 043107 (2008).

${ }^{11}$ A. Wagenpfahl, D. Rauh, M. Binder, C. Deibel, and V. Dyakonov, Phys. Rev. B 82, 115306 (2010).

${ }^{12}$ D. Cheyns, J. Poortmans, P. Heremans, C. Deibel, S. Verlaak, B. P. Rand, and J. Genoe, Phys. Rev. B 77, 165332 (2008).

${ }^{13}$ Y. X. Wang, S. R. Tseng, H. F. Meng, K. C. Lee, C. H. Liu, and S. F. Horng, Appl. Phys. Lett. 93, 133501 (2008).

${ }^{14}$ Z. R. Hong, C. J. Liang, X. Y. Sun, and X. T. Zeng, J. Appl. Phys. 100, 093711 (2006).

${ }^{15}$ P. Peumans and S. R. Forrest, Appl. Phys. Lett. 79, 126 (2001).

${ }^{16}$ Y. Kinoshita, R. Takenaka, and H. Murata, Appl. Phys. Lett. 92, 243309 (2008).

${ }^{17}$ M. Rusu, J. Strotmann, M. Vogel, M. C. Lux-Steiner, and K. Fostiropoulos, Appl. Phys. Lett. 90, 153511 (2007).

${ }^{18}$ S. Heutz, P. Sullivan, B. M. Sanderson, S. M. Schultes, and T. S. Jones, Sol. Energy Mater. Sol. Cells 83, 229 (2004).

${ }^{19}$ Q. L. Song, M. L. Wang, E. G. Obbard, X. Y. Sun, X. M. Ding, X. Y. Hou, and C. M. Li, Appl. Phys. Lett. 89, 251118 (2006).

${ }^{20}$ N. Wang, J. Yu, Y. Zang, J. Huang, and Y. Jiang, Sol. Energy Mater. Sol. Cells 94, 263 (2010).

${ }^{21}$ A. Hamed, Y. Y. Sun, Y. K. Tao, R. L. Meng, and P. H. Hor, Phys. Rev. B 47, 10873 (1993).

${ }^{22}$ P. Sullivan and T. S. Jones, Org. Electron. 9, 656 (2008).

${ }^{23}$ Y. Kanai, T. Matsushima, and H. Murata, Thin Solid Films 518, 537 (2009).

${ }^{24}$ R. Franke, B. Maennig, A. Petrich, and M. Pfeiffer, Sol. Energy Mater. Sol. Cells 92, 732 (2008).

${ }^{25}$ R. Lessmann, Z. Hong, S. Scholz, B. Maennig, M. K. Riede, and K. Leo, Org. Electron. 11, 539 (2010).
${ }^{26}$ I. Bruder, J. Schöneboom, R. Dinnebier, A. Ojala, S. Schäfer, R. Sens, P. Erk, and J. Weis, Org. Electron. 11, 377 (2010).

${ }^{27}$ A. Klein, T. Mayer, A. Thissen, and W. Jaegermann, Bunsen Magazin 10, 124 (2008).

${ }^{28}$ J. A. Barker, C. M. Ramsdale, and N. C. Greenham, Phys. Rev. B 67, 75205 (2003).

${ }^{29}$ J. Williams and A. B. Walker, Nanotech. 19, 424011 (2008).

${ }^{30}$ L. J. A. Koster, E. C. P. Smits, V. D. Mihailetchi, and P. W. M. Blom, Phys. Rev. B 72, 85205 (2005).

${ }^{31}$ T. Kirchartz, B. Pieters, K. Taretto, and U. Rau, J. Appl. Phys. 104, 094513 (2008).

${ }^{32}$ R. Häusermann, E. Knapp, M. Moos, N. Reinke, T. Flatz, and B. Ruhstaller, J. Appl. Phys. 106, 104507 (2009).

${ }^{33}$ M. Zeman, J. van den Heuvel, B. E. Pieters, M. Kroon, and J. Willemen, Advanced Semiconductor Analysis (TU Delft, Delft, 2003).

${ }^{34}$ F. Neumann, Y. A. Genenko, and H. von Seggern, J. Appl. Phys. 99, 013704 (2006).

${ }^{35}$ N. C. Giebink, G. P. Wiederrecht, M. R. Wasielewski, and S. R. Forrest, Phys. Rev. B 82, 155305 (2010).

${ }^{36}$ P. Langevin, Ann. Chim. Phys. 28, 433 (1903).

${ }^{37}$ G. J. Adriaenssens and V. I. Arkhipov, Solid State Commun. 103, 541 (1997).

${ }^{38}$ A. Pivrikas, G. Juška, A. J. Mozer, M. Scharber, K. Arlauskas, N. S. Sariciftci, H. Stubb, and R. Österbacka, Phys. Rev. Lett. 94, 176806 (2005).

${ }^{39}$ C. Deibel, A. Wagenpfahl, and V. Dyakonov, Phys. Rev. B 80, 075203 (2009).

${ }^{40}$ G. Garcia-Belmonte and J. Bisquert, Appl. Phys. Lett. 96, 113301 (2010).

${ }^{41}$ M. Tachiya and K. Seki, Phys. Rev. B 82, 085201 (2010).

${ }^{42}$ N. C. Giebink, B. E. Lassiter, G. P. Wiederrecht, M. R. Wasielewski, and S. R. Forrest, Phys. Rev. B 82, 155306 (2010).

${ }^{43}$ M. M. Mandoc, F. B. Kooistra, J. C. Hummelen, B. de Boer, and P. W. M. Blom, Appl. Phys. Lett. 91, 263505 (2007).

${ }^{44}$ R. A. Street, M. Schoendorf, A. Roy, and J. H. Lee, Phys. Rev. B 81, 205307 (2010).

${ }^{45}$ T. Kirchartz, B. E. Pieters, J. Kirkpatrick, U. Rau, and J. Nelson, Phys. Rev. B 83, 115209 (2011).

${ }^{46}$ P. Schilinsky, C. Waldauf, J. Hauch, and C. J. Brabec, J. Appl. Phys. 95, 2816 (2004).

${ }^{47}$ J. Xue, S. Uchida, B. P. Rand, and S. R. Forrest, Appl. Phys. Lett. 84, 3013 (2004).

${ }^{48}$ K. Harada, A. G. Werner, M. Pfeiffer, C. J. Bloom, C. M. Elliott, and K. Leo, Phys. Rev. Lett. 94, 36601 (2005).

${ }^{49}$ C. Deibel and A. Wagenpfahl, Phys. Rev. B 82, 207301 (2010).

${ }^{50}$ R. A. Street, Phys. Rev. B 82, 207302 (2010).

${ }^{51}$ R. E. I. Schropp and M. Zeman, Amorphous and Microcrystalline Silicon Solar Cells: Modeling, Materials, and Device Technology (Kluwer Academic Publishers, Dordrecht, 1998).

${ }^{52}$ R. N. Hall, Phys. Rev. 87, 387 (1952).

${ }^{53}$ W. Shockley, Phys. Rev. 87, 835 (1952).

${ }^{54}$ C. T. Sah and W. Shockley, Phys. Rev. 109, 1103 (1958).

${ }^{55}$ J. A. Willemen, Ph.D. thesis, University of Delft (1998).

${ }^{56}$ S. Dongaonkar, J. D. Servaites, G. M. Ford, S. Loser, J. Moore, R. M. Gelfand, H. Mohseni, H. W. Hillhouse, R. Agrawal, M. A. Ratner, T. J. Marks, M. S. Lundstrom, and M. A. Alam, J. Appl. Phys. 108, 124509 (2010). 
${ }^{57}$ A. Petersen, S. Schäfer, J. Kostka, T. A. Wagner, and T. Kirchartz (unpublished).

${ }^{58}$ L. A. A. Pettersson, L. S. Roman, and O. Inganäs, J. Appl. Phys. 86, 487 (1999).

${ }^{59}$ H. Bässler, Phys. Status Solidi B 175, 15 (1993).

${ }^{60}$ C. Deibel, T. Strobel, and V. Dyakonov, Phys. Rev. Lett. 103, 36402 (2009).

${ }^{61}$ B. Männig, Ph.D. thesis, TU Dresden (2004).

${ }^{62}$ W. Gao and A. Kahn, Org. Electron. 3, 53 (2002).

${ }^{63}$ R. W. Lof, M. A. van Veenendaal, B. Koopmans, H. T. Jonkman, and G. A. Sawatzky, Phys. Rev. Lett. 68, 3924 (1992).

${ }^{64}$ P. Peumans, A. Yakimov, and S. R. Forrest, J. Appl. Phys. 93, 3693 (2003).

${ }^{65}$ Y. Gassenbauer, R. Schafranek, A. Klein, S. Zafeiratos, M. Hävecker, A. Knop-Gericke, and R. Schlögl, Phys. Rev. B 73, 245312 (2006).

${ }^{66}$ Y. Gassenbauer and A. Klein, J. Phys. Chem. B 110, 4793 (2006).

${ }^{67}$ A. Klein, C. Körber, A. Wachau, F. Säuberlich, Y. Gassenbauer, R. Schafranek, S. P. Harvey, and T. O. Mason, Thin Solid Films 518, 1197 (2009).

${ }^{68}$ Y. C. Zhou, Z. T. Liu, J. X. Tang, C. S. Lee, and S. T. Lee, J. Electron Spectrosc. Relat. Phenom. 174, 35 (2009).

${ }^{69}$ T. Ng, M. Lo, Y. Zhou, Z. Liu, C. Lee, O. Kwon, and S. Lee, Appl. Phys. Lett. 94, 193304 (2009).

${ }^{70}$ C. Hein, E. Mankel, T. Mayer, and W. Jaegermann, Sol. Energy Mater. Sol. Cells 94, 662 (2010).

${ }^{71}$ C. C. Wu, C. I. Wu, J. C. Sturm, and A. Kahn, Appl. Phys. Lett. 70, 1348 (1997).

${ }^{72}$ C. N. Li, A. B. Djurišić, C. Y. Kwong, P. T. Lai, W. K. Chan, and S. Y. Liu, Appl. Phys. A: Mater. Sci. Process. 80, 301 (2005).

${ }^{73}$ A. B. Djurišić, C. Y. Kwong, P. C. Chui, and W. K. Chan, J. Appl. Phys. 93, 5472 (2003).
${ }^{74}$ J. Xue and S. R. Forrest, J. Appl. Phys. 95, 1869 (2004).

${ }^{75}$ A. Walsh and C. R. A. Catlow, J. Mater. Chem. 20, 10438 (2010).

${ }^{76}$ M. V. Hohmann, P. Agoston, A. Wachau, T. J. M. Bayer, J. Brötz, K. Albe, and A. Klein, J. Phys. Condens. Matter (to be published).

${ }^{77}$ A. Walsh, J. L. Da Silva, S. H. Wei, C. Körber, A. Klein, L. F. Piper, A. DeMasi, K. E. Smith, G. Panaccione, P. Torelli, D. J. Payne, A. Bourlange, and E. G. Egdell, Phys. Rev. Lett. 100, 167402 (2008).

${ }^{78}$ D. J. Milliron, I. G. Hill, C. Shen, A. Kahn, and J. Schwartz, J. Appl. Phys. 87, 572 (2000).

${ }^{79}$ J. S. Kim, B. Lägel, E. Moons, N. Johansson, I. D. Baikie, W. R. Salaneck, R. H. Friend, and F. Cacialli, Synth. Met. 111, 311 (2000).

${ }^{80}$ R. Schlaf, H. Murata, and Z. H. Kafafi, J. Electron Spectrosc. Relat. Phenom. 120, 149 (2001).

${ }^{81}$ S. M. Tadayyon, H. M. Grandin, K. Griffiths, L. L. Coatsworth, P. R. Norton, H. Aziz, and Z. D. Popovic, Org. Electron. 5, 199 (2004).

${ }^{82}$ B. Claflin and H. Fritzsche, J. Electron. Mater. 25, 1772 (1996).

${ }^{83}$ H. Fritzsche, B. Pashmakov, and B. Claflin, Sol. Energy Mater. Sol. Cells 32, 383 (1994).

${ }^{84}$ C. Xirouchaki, G. Kiriakidis, T. F. Pedersen, and H. Fritzsche, J. Appl. Phys. 79, 9349 (2009).

${ }^{85}$ T. Takahashi, S. Suzuki, T. Morikawa, H. Katayama-Yoshida, S. Hasegawa, H. Inokuchi, K. Seki, K. Kikuchi, S. Suzuki, K. Ikemoto, and Y. Achiba, Phys. Rev. Lett. 68, 1232 (1992).

${ }^{86}$ L. Bergmann, C. Schaefer, and R. Kassing, Lehrbuch der Experimentalphysik: Festkörper (Walter de Gruyter, Berlin, 2005).

${ }^{87}$ A. Kahn, N. Koch, and W. Gao, J. Polym. Sci., Part B: Polym. Phys. 41, 2529 (2003).

${ }^{88}$ P. Würfel, Physics of Solar Cells (Wiley-VCH, New York, 2005). ${ }^{89}$ N. Tessler and Y. Roichman, Org. Elec. 6, 200 (2005).

${ }^{90}$ N. Li, B. E. Lassiter, R. R. Lunt, G. Wei, and S. R. Forrest, Appl. Phys. Lett. 94, 023307 (2009). 